\title{
2011/27
}

The natalist bias of pollution control

David de la Croix and Axel Gosseries

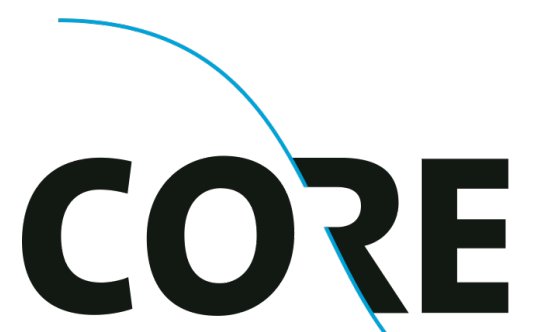

DISCUSSION PAPER

Center for Operations Research and Econometrics

Voie du Roman Pays, 34 B-1348 Louvain-la-Neuve Belgium http://www.uclouvain.be/core 


\title{
CORE DISCUSSION PAPER
}

$2011 / 27$

\section{The natalist bias of pollution control}

\author{
David DE LA CROIX ${ }^{1}$ and \\ Axel GOSSERIES ${ }^{2}$
}

June 2011

\begin{abstract}
For a given technology, two ways are available to achieve low polluting emissions: reducing production per capita or reducing population size. This paper insists on the tension between the former and the latter. Controlling pollution either through Pigovian taxes or through tradable quotas schemes encourages agents to shift away from production to tax free activities such as procreation and leisure. This natalist bias will deteriorate the environment further, entailing the need to impose ever more stringent pollution rights per person. However, this will in turn gradually impoverish the successive generations: population will tend to increase further and production per capita to decrease as the generations pass. One possible solution consists in capping population too.
\end{abstract}

Keywords: overlapping generations, environmental policy, endogenous fertility, quantity quality tradeoff, population control.

JEL Classification: Q58, Q56, J13, O41

\footnotetext{
${ }^{1}$ Université catholique de Louvain, CORE and IRES, B-1348 Louvain-la-Neuve, Belgium.

E-mail: david.delacroix@uclouvain.be. This author is also member of ECORE, the association between CORE and ECARES.

${ }^{2}$ Fonds de la Recherche Scientifique (Belgium) and Hoover Chair, UCLouvain, Belgium.

E-mail: axel.gosseries@uclouvain.be

The authors acknowledge the financial support of the Belgian French speaking community (ARC convention 09-14018 on "Sustainability") and the Belgian Federal Government (Grant PAI P6/07 "Economic Policy and Finance in the Global Economy: Equilibrium Analysis and Social Evaluation."). We thank participants to the IRES macro lunch seminar and to the conference on "Optimal Fertility" (Vienna, 2010), Thierry Bréchet, Jean-François Fagnart, Alexia Fürnkranz-Prskawetz, Wolfgang Lutz, Fabio Mariani, Aude Pommeret, Miguel Sanchez-Romero and two anonymous referees for comments on an earlier draft.

This paper presents research results of the Belgian Program on Interuniversity Poles of Attraction initiated by the Belgian State, Prime Minister's Office, Science Policy Programming. The scientific responsibility is assumed by the authors.
} 


\section{Introduction}

Pollution control can be justified on both efficiency and fairness grounds. Under a Kyoto type of regime, a key motivation for capping greenhouse gas emissions arises from a concern for future generations. The aim is to make sure that the climatic conditions they will experience either be not worse than ours or, at the very least, don't prevent them from leading a decent life. Article 2 of the 1997 Kyoto Protocol states that it aims at the

"stabilization of greenhouse gas concentrations in the atmosphere at a level that would prevent dangerous anthropogenic interference with the climate system. Such a level should be achieved within a time-frame sufficient to allow ecosystems to adapt naturally to climate change, to ensure that food production is not threatened and to enable economic development to proceed in a sustainable manner."

The assumption is thus that people in the future will be better off, climatically speaking, if we cap emissions from now on, than under a business as usual scenario. This is a very plausible claim. And yet, it generates concerns.

One worry has to do with the opportunity cost for today's poor of such pollution control. The worry we are going to deal with here is the reverse one. It is not so much that pollution control may "impoverish" today's poor if certain conditions are met. It is rather that it may "impoverish" future generations too, including their poorest members. Now, the mechanism through which future generations might become poorer as a result of pollution control rests on the demographic impact of the latter. In general, the literature in climate economics tends to operate under the assumption that demographics is exogenous (adopting for example global population size projections made by major demographic institutions). One exception consists in the attempt to connect demographics with the choice of allocation rule of tradable quotas. Consider the following two quotes as illustrations:

"The major objections to [per capita entitlements] are based partly on ethical and practical 'comparable-burden' type arguments (since it would imply a huge adjustment burden on industrialized countries, to which they are unlikely to agree), and partly on grounds of concern that such allocation might 'reward' population and population growth. Proponents tend to argue that any such effect is negligible compared to other factors influencing population; but to avoid any inducement to population growth, Grubb suggests that the population measure 
should be restricted to population above a certain age. (...) Grubb et al. note a wider range of possibilities for avoiding any incentive to population growth, including 'lagged' allocation (related to population a fixed period earlier); apportionment to a fixed historical date; or the inclusion of an explicit term related inversely to population growth rate" (Grubb (1995): 485-486).

"If we agree that emissions allocations should be based on numbers of people, we effectively encourage something which compounds our problems on Earth: population growth. Solutions have been suggested; in particular, we might tie allocations to population figures for a specific time. Singer, for example, argues that per capita allocations should be based on estimates of a country's population in the future, to avoid penalizing countries with young populations." (Garvey (2008): 218).

Although none of these quotes is entirely explicit about the mechanism through which per capita allocation incentivizes population growth, one may assume that what these two authors have in mind is the following idea: under a fully or partly population-based allocation rule of pollution rights, countries are happy with letting their population grow because this will positively impact on their relative share in the quota allocation at the next period. This "share preservation/increase" motive can be one incentive for population growth. Grubb is probably right: if this is what actually drives the natalist effect, it is likely to remain "negligible", as population growth may also entail costs likely to more than compensate the value of getting extra emission entitlements.

The mechanism we have in mind differs from the "share reservation/increase" motive. Moreover, its impact is likely to be much more significant. Our starting point is that, when there is only one production sector, capping emissions entails capping production. We will show that this generates a shift from production to other activities, especially procreation. It is this shift from production to reproduction that will generate the demographic impact of capping emissions. Note that in this case, what drives the natalist effect does not directly have to do with the allocation formula. It rather has to do more directly with the very existence of a cap.

As mentioned above, endogenous responses of population have been neglected so far in environmental economics. The main contribution of our paper is accordingly to provide a framework where demography reacts to pollution control. In order to properly focus on that aspect, we simplify matters with regard to technology, and more specifically, to its degree 
of eco-efficiency. We keep it exogenous. This does not need to imply that technology is constant, but rather that technological progress does not depend on the conducted policy.

One may object that assuming exogenous technology is far fetched. Admittedly, a portion of technical change is endogenous. However, the empirical literature suggests that this portion is limited. ${ }^{1}$ Moreover, there is a second way in which our assumption is realistic: in cases such as climate change, the scale of environment-saving improvements required to stabilize pollution is daunting, at least in the medium-run. Even fully endogenous and highly responsive technology may therefore not suffice.

The essential ingredients of the model are as follows. Individuals allocate their time across three activities: production, leisure, and procreation. Each of these concepts has a specific meaning. Production refers to the time spent on manufacturing consumption and investment goods with an autonomous technology. Leisure involves non-market and emission free activities, such as chatting with friends, sleeping, sweeping the floor,... but could also be extended to include time spent on eco-friendly production activities. ${ }^{2}$ Procreation refers to the time spent on child rearing by parents.

Substitution of procreation for production is at the heart of this paper. It occurs as soon as rearing children takes time ${ }^{3}$ and is sensitive to the relative return of spending time on this or other activities. Various factors can affect this relative return: parents' income (Becker and Lewis 1973), child mortality (Bar and Leukhina (2010) and Doepke (2005)), the absence of formal old age support schemes (Ehrlich and Lui 1991), cultural norms (Princeton European Fertility Project), the importance of increasing the relative power of one's community (see Toft (2002) and de la Croix and Dottori (2008)), etc. In this paper we concentrate on the first of these factors. Becker and Lewis (1973) stress that the wage of the parents is part of the opportunity cost of having children. A rise in parents wage leads to a substitution of production for procreation, and to drop of fertility. Such a mechanism is seen by many economists as a key explanation of the demographic transition (for a recent critical survey see Jones, Schoonbroodt, and Tertilt (2010)). If wages are so important for fertility out-

\footnotetext{
${ }^{1}$ The impact of environmental prices and policy on technological choice by firms has been studied by many. It seems that while some innovation was responsive to energy price changes, a sizable portion of efficiency improvements were still autonomous (see Newell, Jaffe, and Stavins (1999)). In addition, although environmental taxes reduce pollution by encouraging the development of new technologies, simply relying on technological change as a panacea for environmental problems is not enough (see Popp (2002)).

${ }^{2}$ Leisure is a non essential ingredient of the model. Its inclusion ensures the robustness of the results to the existence of a diversity of activities allowing at every moment in time to shift from eco-efficient activities to less eco-intensive ones.

${ }^{3}$ More precisely, the key assumption is that time costs is much more significant than goods costs in the case of child rearing. In the model, we abstract from goods costs, which does not impact on our results as long as such costs remain relatively smaller.
} 
comes, taxes on wages are relevant too. Pollution control policy, either explicitly through a Pigovian tax, or implicitly through a tradable quota scheme, implies a drop in the net wage of those working in the final good sector. For households, production becomes relatively more expensive through the conjunction of the tax resulting from the cap and the absence of such a tax on procreation and leisure. Agents then tend to substitute reproduction and leisure to production. As a result, unless substitution is exclusively of a production - leisure type, population will tend to increase and production per worker to decrease.

How strong is this substitution effect? Many empirical studies show that fertility is negatively related to mothers' wages or education. ${ }^{4}$ This tends to confirm that opportunity costs such as women's income are essential to determine fertility. However, even if this mechanism were weak it would not matter much for our purpose. This is because our time horizon is long. The cumulative impact on population of even a weak substitution effect is indeed likely to be significant.

When, in addition to choosing the number of children, parents also choose the quality of these children, capping pollution will have additional effects. Quality of children amounts to future productivity and is the result of investment in education, health etc. which we distinguish from "mere" child rearing. Many authors rely on the notion of a quantity-quality tradeoff, introduced by Becker (1960), to explain the rise in education and the fertility decline during the demographic transition: as the economy grows and wages rise the opportunity cost of child rearing increases. At the same time, rising income implies that investment in education becomes more affordable. Parents therefore substitute child quality for child quantity, and decide to have smaller families with better education (see e.g. Doepke (2004)) In the case of environmental policy, this mechanism goes in the opposite direction. Taxing production lowers the wages, decreases the opportunity cost of raising children but increases the cost of education relative to the wage. Parents would therefore substitute child quantity for child quality, and decide to have larger and less educated families. In the case of developing countries in the middle of their demographic transition, taxing pollution, and therefore production and income, is thus expected to delay the drop in fertility and the rise in education, going in the opposite direction to what is suggested in the literature, i.e., taxing birth and subsidizing education (Fan and Stark (2008), Shi and Zhang (2009)).

In Section 2 we introduce pollution dynamics into a standard model of fertility with a quality-quantity tradeoff. In Section 3 we set a pollution cap and analyze the dynamics of population and income under such a policy. A numerical experiment is provided in Section 4

\footnotetext{
${ }^{4}$ For example, Fernández and Fogli (2006) for migrants in the US Deb and Rosati (2004) for India and Baudin (2009) for France.
} 
aimed at illustrating and quantifying the main effects derived in the previous sections. The last section concludes.

\section{The Benchmark Model}

Time is discrete and goes from 0 to infinity. Each individual only lives for two periods: childhood and (active) adulthood. We consider a closed economy, possibly the whole Earth, endowed with a certain quantity of land $L$, having an initial level of human capital per person $k_{0}$, an adult population size $N_{0}$, and an initial pollution level $P_{-1}$. We first describe how pollution is generated. Then we consider the household maximization problem and, finally, the implied aggregate dynamics.

\subsection{Production and Pollution}

At a given time, for a given technology, polluting emissions $E_{t}$ are proportional to total output $Y_{t}$ :

$$
E_{t}=a_{t} Y_{t}
$$

Variable $a_{t}$ represents the pollution coefficient, i.e. the degree to which production generates polluting emissions. Total output is itself the product of adult population size $N_{t}$ and production per person $y_{t}$ :

$$
E_{t}=a_{t} N_{t} y_{t}
$$

This equation is known in the literature as the Kaya identity. If $E_{t}$ is measured in tons of $\mathrm{CO}_{2}$, then $a_{t}$ would be tons of $\mathrm{CO}_{2}$ per dollar produced. The stock of pollution $S_{t}$ accumulates according to:

$$
S_{t}=\Psi\left(S_{t-1}, E_{t}\right), \quad \forall t \in \mathbb{N}
$$

The function $\Psi($.$) takes different forms in the literature. { }^{5}$ Figure 1 displays a map of isopollution curves. Each curve represents a constant pollution level in the plane population $\times$ income per person. As we follow the curve towards the right, income per person decreases and population increases, pollution remaining constant. In order to move from one isopollution curve to another with lower level of emissions, one may of course lower production

\footnotetext{
${ }^{5}$ See for example John and Pecchenino (1994) where pollution is the inverse of an "environment" variable which accumulates like capital, assuming some positive degradation rate, i.e., the share of past pollution $S_{t-1}$ that has been absorbed by the environment. In Howarth (1998), a "world temperature" variable is like pollution here and depends on the past emissions.
} 
per capita and/or lower population size; however, one could even increase any of the two if the other gets reduced strongly enough.

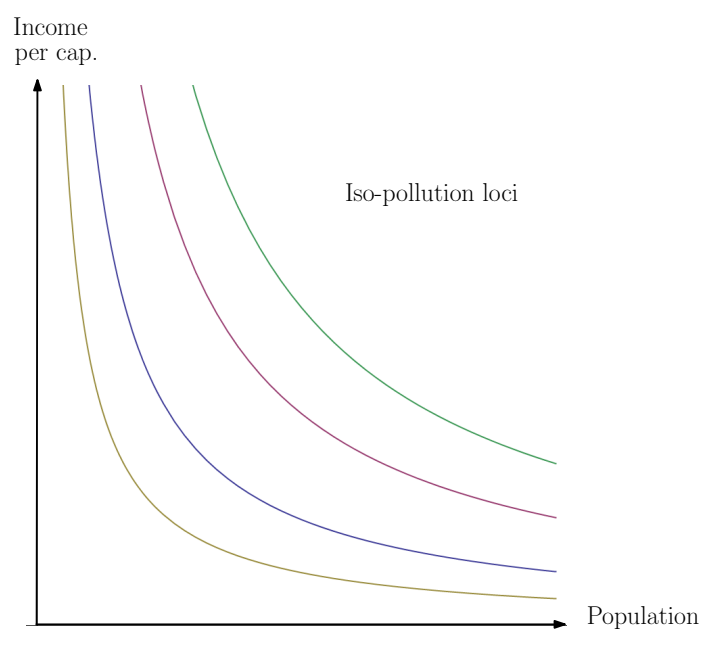

Figure 1: Map of Iso-pollution Curves

Over time, the map can change. Two factors affect the position of the curves. On the one hand, technical progress allowing to produce the same amount with a cleaner technology and lower emissions (for example through higher energy efficiency) shifts the iso-pollution curves to the North-East. Environmental efficiency decreases the pollution coefficient $a_{t}$. On the other hand, if there is more pollution accumulated in the past $\left(S_{t-1}\right)$, the iso-pollution curves of today will shift to the South-West. Figure 2 represents these two possible shifts.

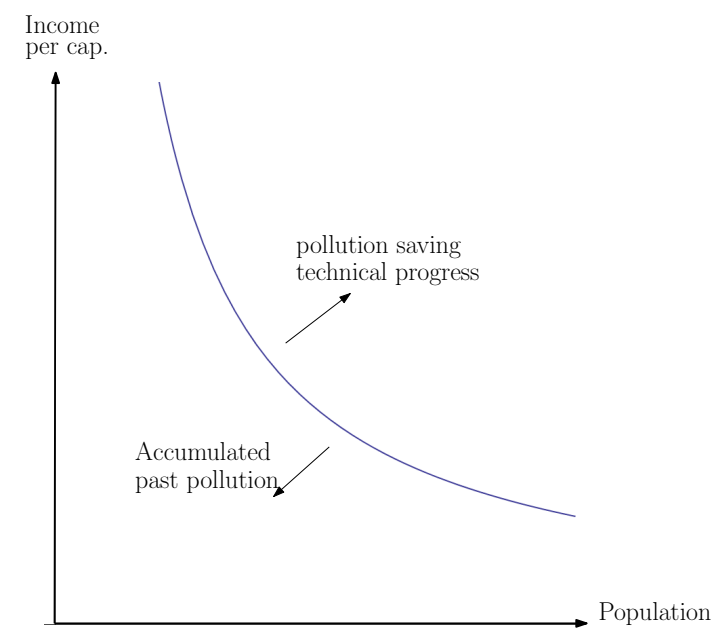

Figure 2: Shifts over Time of one Iso-pollution Curve 


\subsection{Households}

At each date $t$, there is a new adult generation of size $N_{t}$ deriving utility from consumption $c_{t}$, leisure $\ell_{t}$, number of children $n_{t}$, and quality of the children $k_{t+1}$, as measured by their future human capital. Households are homogeneous. We assume a logarithmic utility function

$$
u\left(c_{t}, \ell_{t}, n_{t}, k_{t+1}\right)=\ln c_{t}+\varphi \ln \ell_{t}+\gamma \ln \left(n_{t} k_{t+1}\right),
$$

with $\varphi, \gamma \in \mathbb{R}_{+}$. Parameter $\varphi$ is the taste for leisure. Parameter $\gamma$ is the altruism factor. Parents care both about child quantity $n_{t}$ and quality $k_{t+1}$, as measured by the human capital provided to them. Notice that parents do not care about their children utility, as it would be the case with dynastic altruism. Our formulation of altruism is referred in the literature as "joy-of-giving" (or warm glove), because parents have a taste for giving (see e.g. Andreoni (1989)). As our aim here is not to assess how agents should behave, impure altruism seems an acceptable assumption as a mean to obtain clearcut analytical results.

The choice of a logarithmic utility function is defended by Prescott (1986) on the grounds that leisure showed no secular trend despite growing wages. This can only be accounted for when the elasticity of substitution between leisure and consumption is close to one.

We do not introduce pollution into the utility, because our objective is not to derive the best policy, but rather to show the side effects of a given type of policy, the one that consists in taxing pollution. Adding a disutility term such as $-v(S)$ to the utility would not change any of our results as long as utility is additively separable.

Future human capital is obtained through spending on education, $e_{t}$. Human capital production function is:

$$
k_{t+1}=\tau e_{t}^{\eta} k_{t}^{\nu}
$$

with the following parametric restrictions: $\tau \in \mathbb{R}_{+}, \nu, \eta \in(0,1)$. We assume moreover that $\eta+\nu<1$, which will imply that human capital and output per person will converge in the long-run to a constant level. ${ }^{6}$ Parameter $\tau$ is a measure of productivity of education technology. Parameter $\eta$ is the elasticity of human capital $k_{t+1}$ to investment $e_{t}$. Parameter $\nu$ captures the strength of an externality from parents human capital to children human capital.It represents the usual parental influence on children outcome. This production function is very standard in the literature on education, starting with Glomm and Ravikumar (1992).

\footnotetext{
${ }^{6}$ The alternative case $\eta+\nu=1$ would generate endogenous growth, which could be analyzed as well with the tools developed here.
} 
Let us provide a few additional details on the parameters $\eta$ and $\nu . \eta$ measures the elasticity of earnings with respect to schooling. An idea of its magnitude can be obtained from the survey by Krueger and Lindahl (2001) which reports estimates of the return to schooling in developed countries of 8-10 percent, with higher estimates for developing countries and low levels of schooling. Assuming that an additional year of schooling raises education expenditure by 20 percent, these returns translate into an earnings elasticity of schooling between 0.4 and 0.8 . Replacing $k_{t+1}$ in the utility function by its expression from (1), allows to stress the importance of the parameter $\eta$ :

$$
\ln \left(c_{t}\right)+\varphi \ln \ell_{t}+\gamma\left(\ln \left(n_{t}\right)+\eta \ln \left(e_{t}\right)\right)+\gamma \nu \ln k_{t}+\gamma \tau
$$

The last two terms of the sum are constant. We see that $\eta$ is not only the elasticity of human capital to education spending in (1), but also the relative weight of quality in the utility function. It has to be smaller than 1 because the parents' optimization problem would otherwise not have a solution. More specifically, utility would approach infinity as parents choose arbitrarily high levels of quality spending $e_{t}$ and arbitrarily low levels of fertility (a similar condition can be found in Moav (2005) and de la Croix and Doepke (2009)).

The parameter $\nu$ captures the intergenerational transmission of ability, as well as human capital formation within the family that does not work through formal schooling $\left(e_{t}\right)$. Empirical studies detect such effects, but they are relatively small. ${ }^{7}$

Producing $x$ children requires time $T_{t}$ and space $L / N_{t}$ (land per household), with the following technology:

$$
x=\mu\left(\frac{L}{N_{t}}\right)^{\alpha} T_{t}
$$

Compared to the models developed in the recent literature, we introduce land per person as an input in the child production technology. The aim is to take into account that, when households have small dwellings, child production is more costly and people have fewer children (this is known since Goodsell (1937) and Thompson (1938)). It also implies that population will be stationary in the long-run. Indeed, as population increase, it becomes more and more costly to have children, lowering progressively the fertility rate to its replacement level. Parameter $\mu$ measures total factor productivity of the procreation activity. Parameter $\alpha \in(0,1)$ captures the importance of space to produce children. The time needed to produce $n_{t}$ children is given by:

$$
\frac{1}{\mu}\left(\frac{N_{t}}{L}\right)^{\alpha} n_{t}=\phi N_{t}^{\alpha} n_{t},
$$

\footnotetext{
${ }^{7}$ For example, Leibowitz (1974) finds that, after controlling for education, parental income has a significant effect on a child's earnings. The elasticity is of the order of 0.1 .
} 
with

$$
\phi=\frac{1}{\mu}\left(\frac{1}{L}\right)^{\alpha} .
$$

Households face a budget constraint stating that consumption plus education spending cannot exceed income $y_{t}$ :

$$
c_{t}+n_{t} e_{t} \leq y_{t}
$$

Households have a total time endowment equal to 1. They face a time constraint, expressing that time spent working $h_{t}$, rearing children and having leisure should not exceed 1.

$$
h_{t}+\phi N_{t}^{\alpha} n_{t}+\ell_{t} \leq 1
$$

Households are self-employed. The productivity of each hour of work is given by the quality of the worker, i.e. his/her human capital $k_{t}$. Total production is therefore the product of hours of work $h_{t}$ and $k_{t}$ :

$$
y_{t} \leq h_{t} k_{t}
$$

Notice that, in this production function, we assume constant returns with respect to input of efficiency units $h_{t} k_{t}$. We also consider hours of work and efficiency units a perfect substitutes: doubling efficiency together with halving hours of work would leave production unchanged. Departing from one of these two assumptions is not expected to modify the results. However, it would make the analysis more complex, requiring to rely on numerical analysis in most cases.

Replacing the saturated constraints (2), (3) and (4) into the objective, the households maximization problem can be written as:

$$
\max _{\ell_{t}, n_{t}, e_{t}} \ln \left(\left(1-\ell_{t}-\phi n_{t}\right) k_{t}-n_{t} e_{t}\right)+\varphi \ln \ell_{t}+\gamma\left(\ln \left(n_{t}\right)+\eta \ln \left(e_{t}\right)\right)+\text { constant terms }
$$

The first order conditions are:

$$
\begin{aligned}
& \frac{-k_{t}}{\left(1-\ell_{t}-\phi n_{t}\right) k_{t}-n_{t} e_{t}}+\frac{\varphi}{\ell_{t}}=0 \\
& \frac{-\phi k_{t}-e_{t}}{\left(1-\ell_{t}-\phi n_{t}\right) k_{t}-n_{t} e_{t}}+\frac{\gamma}{n_{t}}=0 \\
& \frac{-n_{t}}{\left(1-\ell_{t}-\phi n_{t}\right) k_{t}-n_{t} e_{t}}+\frac{\gamma \eta}{e_{t}}=0
\end{aligned}
$$

As the maximization problem is convex, the first-order conditions are necessary and sufficient 
for a maximum. Solving the set of first order conditions and saturated constraints (2)-(3)-(4) for $c_{t}, \ell_{t}, n_{t}, e_{t}$, and $y_{t}$ yields closed form solutions:

$$
\begin{aligned}
c_{t} & =\frac{k_{t}}{1+\varphi+\gamma} \\
\ell_{t} & =\frac{\varphi}{1+\varphi+\gamma} \\
n_{t} & =\frac{\gamma(1-\eta)}{(1+\varphi+\gamma) \phi N_{t}^{\alpha}} \\
e_{t} & =\frac{\eta \phi N_{t}^{\alpha} k_{t}}{1-\eta} \\
y_{t} & =\frac{\gamma \eta}{1+\varphi+\gamma} k_{t}
\end{aligned}
$$

\subsection{Aggregate Dynamics}

Adult population dynamics are given by:

$$
N_{t+1}=N_{t} n_{t}
$$

Replacing the expressions for $e_{t}(8)$ and $n_{t}(7)$ into the equations describing the dynamics of human capital (1) and population (10) leads to:

$$
\begin{aligned}
k_{t+1} & =\tau\left(\frac{\eta \varphi}{1-\eta}\right)^{\eta} N_{t}^{\eta \alpha} k_{t}^{\nu+\eta} \\
N_{t+1} & =\frac{\gamma(1-\eta)}{(1+\varphi+\gamma) \phi} N_{t}^{1-\alpha}
\end{aligned}
$$

This system is recursive as the second equation can be solved independently of the first one. The second equation shows that $N_{t+1}$ is an increasing and concave function of $N_{t}$ which does not depend on $k_{t}$. It has a unique non trivial steady state

$$
\bar{N}=\left(\frac{\gamma(1-\eta)}{(1+\varphi+\gamma) \phi}\right)^{\frac{1}{\alpha}}
$$

which is globally stable. Dynamics of population are monotonic. For a given $N_{t}$, the first equation also describes an increasing and concave relation between $k_{t+1}$ and $k_{t}$. When $N_{t}$ is close enough to $\bar{N}$, the dynamics of $k_{t}$ are also monotonic and converge to:

$$
\bar{k}=\left(\frac{\tau^{1 / \eta} \gamma \eta}{1+\varphi+\gamma}\right)^{\frac{\eta}{1-\nu-\eta}} \quad \text { for } \alpha>0
$$


Income per capita converges to

$$
\bar{y}=\tau^{\frac{1}{1-\nu \eta}}\left(\frac{\gamma \eta}{1+\varphi+\gamma}\right)^{\frac{1-\nu \eta+\eta}{1-\nu \eta}}
$$

A larger country (higher $L$, lower $\phi$ ) will have a larger population size. A more productive country (higher $\tau$ ) will have higher income per capita.

If $\alpha=0$, space is not useful to produce children. Population grows unboundedly at rate $\gamma(1-\eta) /((1+\varphi+\gamma) \phi)$ and human capital converges to:

$$
\bar{k}=\left(\frac{\tau^{1 / \eta} \eta \varphi}{1-\eta}\right)^{\frac{\eta}{1-\nu \eta}} \quad \text { for } \alpha=0
$$

\section{Regulation: Pollution Cap and Tradable Rights}

At each date, past pollution is given. A given pollution target $S_{t}^{\star}$ can be achieved by imposing an emission target $E_{t}^{\star}$ such that:

$$
S_{t}^{\star}=\Psi\left(S_{t-1}^{\star}, E_{t}^{\star}\right), \quad \forall t \in \mathbb{N} .
$$

Since we do not provide, in this paper, a utility based justification for a given pollution target, the latter is taken to be exogenous. As a result, the path of emission targets $\left\{E_{t}^{\star}\right\}_{t=0 . .+\infty}$ is exogenous too.

Remember that, for simplification purposes, we have assumed that the output is produced by self-employed households. To meet the sequence of emission targets, two policy schemes are available and interchangeable. First, a Pigovian tax on emissions, hence on production, the revenue of which is transferred back to households in a lump-sum way. Second, a tradable pollution rights system with a free initial allocation of rights to households. In a world where agents behave competitively and information is perfect about both the objective that is being pursued and the deep parameters of the model, tradable quotas schemes and price-oriented schemes are fully equivalent. ${ }^{8}$ This implies that, despite our focus on tradable right schemes, the results will be of direct relevance for those willing to implement a Pigovian tax.

\footnotetext{
${ }^{8}$ Uncertainty (Weitzman 1974) or strategic interactions (Wirl 2011) draw a wedge between these two instruments.
} 


\subsection{Households}

Tradable pollution rights systems, such as the Kyoto system, impose each household to buy pollution rights in proportion to the output that would exceed their initial endowment. Let us denote the price of the pollution right by $p_{t}$ and the initial endowment of rights by $q_{t}$. The budget constraint of the household is now:

$$
y_{t} \geq c_{t}+n_{t} e_{t}+p_{t}\left(a_{t} y_{t}-q_{t}\right)
$$

The constraint can be rewritten:

$$
\left(1-a_{t} p_{t}\right) y_{t}+p_{t} q_{t} \geq c_{t}+n_{t} e_{t}
$$

which shows clearly that the price of pollution permits $p_{t}$ weighted by the pollution coefficient $a_{t}$ acts like an income tax, and $p_{t} q_{t}$ as a lump sum transfer.

Replacing the saturated constraints (1), (14), (3) and (4) into the objective, the households maximization problem can be written as:

$$
\begin{aligned}
\max _{\ell_{t}, n_{t}, e_{t}} \mathcal{L}_{t}=\ln \left(\left(1-a_{t} p_{t}\right)\left(1-\ell_{t}-\phi n_{t}\right) k_{t}\right. & \left.-n_{t} e_{t}+p_{t} q_{t}\right) \\
& +\varphi \ln \ell_{t}+\gamma\left(\ln \left(n_{t}\right)+\eta \ln \left(e_{t}\right)\right)+\text { constant terms }
\end{aligned}
$$

The first order conditions can be written under the form "marginal cost = marginal benefit":

$$
\begin{array}{llll}
\frac{\partial \mathcal{L}_{t}}{\partial \ell_{t}}=0 & \Rightarrow & & \frac{\left(1-a_{t} p_{t}\right) k_{t}}{c_{t}}=\frac{\varphi}{\ell_{t}} \\
\frac{\partial \mathcal{L}_{t}}{\partial n_{t}}=0 & \Rightarrow & & \frac{\left(1-a_{t} p_{t}\right) \phi k_{t}-e_{t}}{c_{t}}=\frac{\gamma}{n_{t}} \\
\frac{\partial \mathcal{L}_{t}}{\partial e_{t}}=0 & \Rightarrow & \frac{n_{t}}{c_{t}}=\frac{\gamma \eta}{e_{t}}
\end{array}
$$

The price $p_{t}$ affects the first order conditions for $\ell_{t}$ and $n_{t}$ by lowering their marginal cost. As the maximization problem is convex, the first-order conditions are necessary and sufficient for a maximum. Solving the system formed by the first-order conditions and the constraints 
leads to:

$$
\begin{aligned}
c_{t} & =\frac{1}{1+\varphi+\gamma}\left(\left(1-a_{t} p_{t}\right) k_{t}+p_{t} q_{t}\right) \\
\ell_{t} & =\frac{\varphi}{1+\varphi+\gamma} \frac{\left(1-a_{t} p_{t}\right) k_{t}+p_{t} q_{t}}{\left(1-a_{t} p_{t}\right) k_{t}} \\
n_{t} & =\frac{\gamma(1-\eta)}{(1+\varphi+\gamma) \phi N_{t}^{\alpha}} \frac{\left(1-a_{t} p_{t}\right) k_{t}+p_{t} q_{t}}{\left(1-a_{t} p_{t}\right) k_{t}} \\
e_{t} & =\frac{\eta \phi N_{t}^{\alpha} k_{t}}{1-\eta}\left(1-a_{t} p_{t}\right) \\
y_{t} & =\frac{\left(1-a_{t} p_{t}\right) k_{t}(1+\gamma \eta)-(\varphi+\gamma-\gamma \eta) p_{t} q_{t}}{\left(1-a_{t} p_{t}\right)(1+\varphi+\gamma)}
\end{aligned}
$$

\subsection{A Small Open Economy}

Before considering our economy as a model of the world, hence in general equilibrium, we analyze the case of a small open economy in which the price $p_{t}$ and the quota $q_{t}$ are imposed from outside and exogenous.

We first observe that the time spent on emission-free activities, i.e. leisure and procreation, increases with the price of pollution permits $p_{t}$. Indeed, $p_{t}$ acts as a tax on the time spent on production. Hence, increases in $p_{t}$ lower the opportunity cost of leisure and procreation. $p_{t}$ is similar to a subsidy to procreation:

$$
\frac{\partial \ell_{t}}{\partial p_{t}}>0, \quad \frac{\partial n_{t}}{\partial p_{t}}>0
$$

Leisure and procreation also increase with the endowment of pollution permits. This is because they are both normal goods:

$$
\frac{\partial \ell_{t}}{\partial q_{t}}>0, \quad \frac{\partial n_{t}}{\partial q_{t}}>0
$$

Human capital accumulation (education) is reduced by the price of pollution permits, because of a substitution of quantity $\left(n_{t}\right)$ for quality $\left(k_{t+1}\right)$ of children:

$$
\frac{\partial e_{t}}{\partial p_{t}}<0
$$

Finally, net individual income and production are reduced by the price $p_{t}$ :

$$
\frac{\partial y_{t}}{\partial p_{t}}=-\frac{(\varphi+\gamma(1-\eta)) q_{t}}{\left(1-p_{t}\right)^{2}(1+\varphi+\gamma)}<0
$$


Let us now analyze how the presence of tradable pollution rights affects the steady state and the dynamics of a small open economy. For this, we assume exogenous variables to be constant, i.e. $a_{t}=a, p_{t}=p$ and $q_{t}=q$. The dynamics are represented as follows:

$$
\begin{aligned}
k_{t+1} & =\tau\left(\frac{\eta \varphi}{1-\eta}\right)^{\eta} N_{t}^{\eta \alpha} k_{t}^{\nu+\eta}(1-a p)^{\eta} \\
N_{t+1} & =\frac{\gamma(1-\eta)}{(1+\varphi+\gamma) \phi} N_{t}^{1-\alpha} \frac{(1-a p) k_{t}+p q}{(1-a p) k_{t}}
\end{aligned}
$$

This dynamical system is no longer block recursive, i.e. the two difference equations need to be solved simultaneously. To analyze its properties, we can draw the phase diagram of Figure 3. A first phase line is given by

$$
\Delta k_{t+1}=0 \Leftrightarrow k_{t+1}-k_{t}=\tau\left(\frac{\eta \varphi}{1-\eta}\right)^{\eta} N_{t}^{\eta \alpha} k_{t}^{\nu+\eta}(1-a p)^{\eta}-k_{t}=0 .
$$

Solving for $N_{t}$ gives

$$
N_{t}=\tau^{\frac{-1}{\eta \alpha}}\left(\frac{\eta \varphi}{1-\eta}\right)^{\frac{-1}{\alpha}}(1-a p)^{\frac{-1}{\alpha}} k_{t}^{\frac{1-\nu-\eta}{\eta \alpha}} .
$$

The right hand side is an increasing function of $k_{t}$. We draw this function in the space $\left\{k_{t}, N_{t}\right\}$. Considering a point located above that line, i.e. a point with a larger $N_{t}$ than the one given by (18), it appears from (17) that it corresponds to a situation where $\Delta k_{t+1}>0$. Accordingly, when located above this phaseline, we draw a horizontal arrow oriented to the right to indicate the direction of motion. Another arrow oriented to the left is drawn when below then phaseline.

The second phase line is given by

$$
\Delta N_{t+1}=0 \Leftrightarrow N_{t+1}-N_{t}=\frac{\gamma(1-\eta)}{(1+\varphi+\gamma) \phi} N_{t}^{1-\alpha} \frac{(1-a p) k_{t}+p q}{(1-a p) k_{t}}-N_{t}=0
$$

Solving for $N_{t}$ gives

$$
N_{t}=\left[\frac{\gamma(1-\eta)}{(1+\varphi+\gamma) \phi} \frac{(1-a p) k_{t}+p q}{(1-a p) k_{t}}\right]^{\frac{1}{\alpha}}
$$

which is a negatively sloped function going from $+\infty$ when $k_{t}=0$ to 0 when $k_{t}=+\infty$. Let us decrease $k_{t}$ to consider a point to the left of this curve. It increases the function (19) and hence $\Delta N_{t+1}>0$ in this zone. Hence, to the left (resp. right) of this curve, we can draw arrows pointing upward (resp. downward).

The phase diagram in the left panel of Figure 3 shows that there is inevitably a unique steady state with oscillatory dynamics. Appendix A linearizes the dynamic system around 

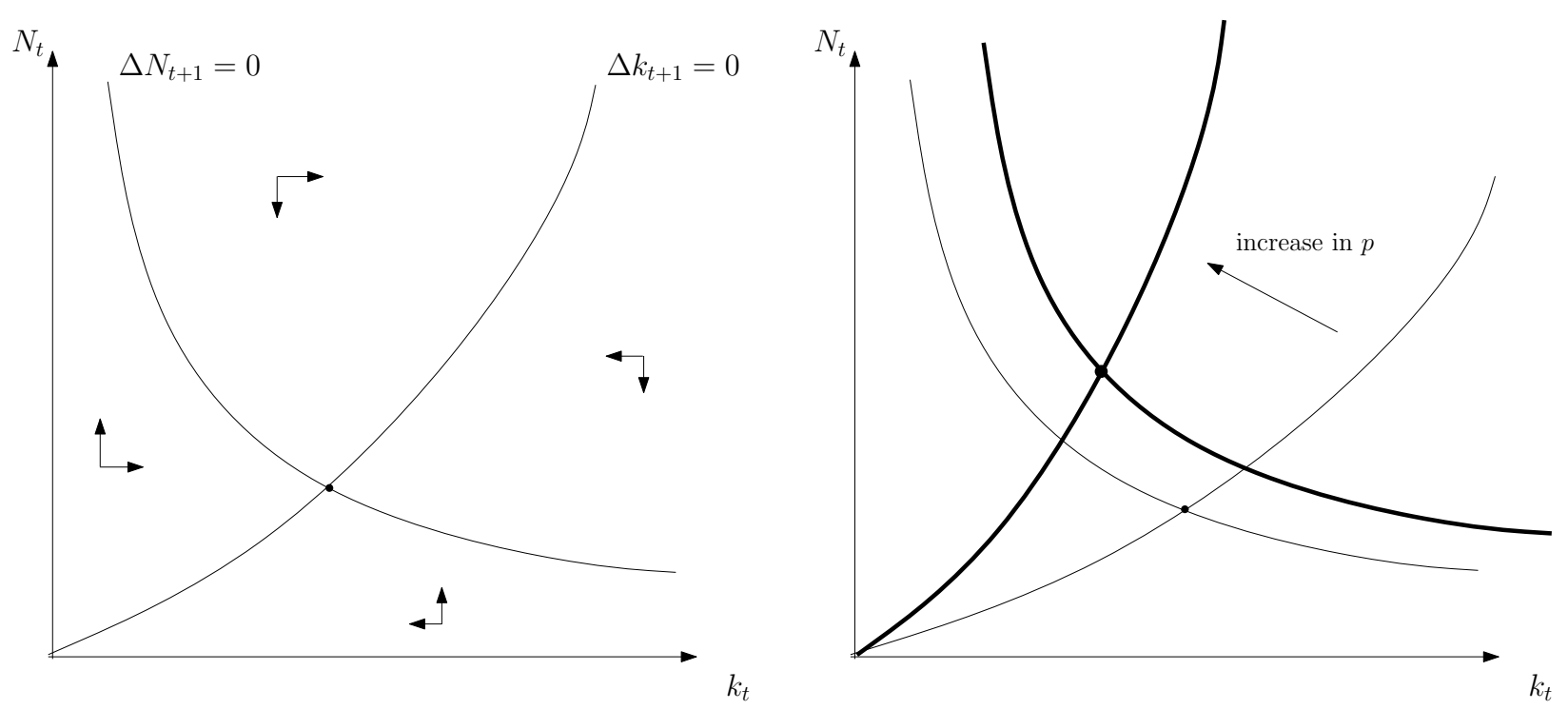

Figure 3: Phase diagram for a small open economy

the steady state and shows that the steady state is locally stable.

Let us now suppose that there is an exogenous increase in the price of pollution permits. Differentiating the two phase lines (18) and (20) leads us to conclude that they both shift upward. As a consequence, the new steady state has a higher population level. We have seen above that pollution control was increasing fertility. This translates at the steady state level into a larger population.

\subsection{General Equilibrium}

We now turn our attention to the most difficult case: the one in which the price of pollution rights, instead of being exogenous, adjust as a function of market forces. The equilibrium on the market for tradable pollution rights implies that total pollution $N_{t} a_{t} y_{t}$ equals the total number of quotas $N_{t} q_{t}$, unless the price $p_{t}$ is nil:

$$
p_{t}\left(N_{t} a_{t} y_{t}-N_{t} q_{t}\right)=0 .
$$

Two cases may arise depending on whether the cap is binding or not. A cap is binding if it is set lower than the otherwise desired total amount of pollution. This occurs when

$$
q_{t}<a_{t} y_{t}
$$


where $y_{t}$ is computed in the business as usual scenario. Replacing $y_{t}$ by its value from Equation (9) leads to:

$$
q_{t}<a_{t} \frac{1+\gamma \eta}{1+\varphi+\gamma} k_{t}
$$

Proposition 1 At time t, the equilibrium satisfies:

$$
\begin{aligned}
\text { If (21) holds then } \quad p_{t} & =\frac{k_{t}(1+\gamma \eta)-q_{t}(1+\varphi+\gamma)}{\left(k_{t}-q_{t}\right)(1+\gamma \eta)} \\
y_{t} & =\frac{q_{t}}{a_{t}} \\
\text { If (21) does not hold then } p_{t} & =0 \\
y_{t} & =\frac{\gamma \eta}{1+\varphi+\gamma} \frac{k_{t}}{q_{t}}
\end{aligned}
$$

If the pollution endowment is sufficiently restrictive, there will be a positive price of pollution permits and production will match the target. If the pollution quota is large, the policy is non binding. The price of permits then falls to zero, and the output corresponds with the one of the business as usual scenario.

\subsection{Dynamics}

Let us consider a constant emission cap $E^{\star}$. As a consequence, the pollution endowment per household will be:

$$
q_{t}=\frac{E^{\star}}{N_{t}}
$$

We now analyze how different levels of the emission cap $E^{\star}$ affect the dynamics of population $N_{t}$. To simplify, we keep technical progress constant $a_{t}=1$ (but of course we will not use this simplification when we will let $a_{t}$ increase in one of our scenarii).

The dynamics of human capital $k_{t}$ and population $N_{t}$ are obtained by replacing $e_{t}, n_{t}$, and $p_{t}$ from (16), (15) and (22) into (1) and (10):

$$
\begin{gathered}
k_{t+1}=\tau k_{t}^{\nu}\left(\frac{\eta \phi N_{t}^{\alpha} k_{t}}{1-\eta}\left(1-\frac{k_{t}(1+\gamma \eta)-q_{t}(1+\varphi+\gamma)}{\left(k_{t}-q_{t}\right)(1+\gamma \eta)}\right)\right)^{\eta} \\
N_{t+1}=N_{t}\left(\frac{\gamma(1-\eta)}{(1+\varphi+\gamma) \phi N_{t}^{\alpha}}\left(1+\frac{\frac{k_{t}(1+\gamma \eta)-q_{t}(1+\varphi+\gamma)}{\left(k_{t}-q_{t}\right)(1+\gamma \eta)}}{1-\frac{k_{t}(1+\gamma \eta)-q_{t}(1+\varphi+\gamma)}{\left(k_{t}-q_{t}\right)(1+\gamma \eta)}} \frac{q_{t}}{k_{t}}\right)\right)
\end{gathered}
$$


Using $q_{t}=E^{\star} / N_{t}$ and simplifying leads to:

$$
\begin{aligned}
k_{t+1} & =\tau k_{t}^{\nu+\eta}\left(\frac{\eta \phi N_{t}^{\alpha} E^{\star}(\varphi+\gamma-\gamma \eta)}{\left(N_{t} k_{t}-E^{\star}\right)(1-\eta)(1+\gamma \eta)}\right)^{\eta} \\
N_{t+1} & =\frac{\gamma(1-\eta)\left(N_{t} k_{t}-E^{\star}\right)}{\phi N_{t}^{\alpha} k_{t}(\varphi+\gamma-\gamma \eta)}
\end{aligned}
$$

The analysis of these dynamics is detailed in Appendix B. The main result is the following.

\section{Proposition 2 (Population and the pollution cap)}

For a sufficiently stringent pollution cap $E^{\star}$, there is a locally stable steady state population, decreasing in $E^{\star}$.

If $E^{\star}$ is restrictive enough, the long-run population $\bar{N}$ is higher if the pollution cap is set at a more stringent level. As a consequence, income per capita will unambiguously be lower, as $y=E^{\star} / N$.

From the dynamic point of view, the pro-population tilt of pollution caps is worrying. For a given $E^{\star}$, emission endowments per person inevitably become more and more stringent as generations pass. Because of this pro natalist effect, capping emissions impoverishes the successive generations more than in a conventional set-up with exogenous fertility. It is worth spelling out why capping emissions tends to reduce production rather than procreation. This is the case because production generates emissions from the moment it takes place onwards, whereas procreation rather generates delayed emissions. This rests on two assumptions. First only physical good production generates pollution. Second, children do not consume physical goods. This implies that the emissions of a person take place at adulthood. In a more general set-up, it would be sufficient to assume that procreation and leisure are simply less emission-intensive activities than production. This is why capping emissions at period $t$ puts less pressure on procreation than on production. In a way, if procreation only generates emissions through future production (i.e. when children will themselves become producers), the capping scheme generates a specific form of externality. Current adults willing to procreate at a rate higher than the replacement rate do not internalize the fact that tomorrow's pollution cap will have to be divided into smaller pollution endowments.

\section{Numerical Experiment}

In order to provide a meaningful example of the mechanisms studied analytically above, we calibrate the parameters of the model and we simulate the effect of introducing pollution 
caps on the dynamics of income and population.

\subsection{Calibration}

Assume that each period lasts 25 years. We will use the year 1983 as representing $t=0$

(initial conditions), and the year 2008 as $t=1$. 2008 is the last year for which we have observations.

We first identify $\gamma, \varphi, \eta, \nu$ and $\alpha$ with the following five restrictions:

1. The share of consumption in GDP is $80 \%$ (corresponds to public and private consumptions of the national accounts). Using Equations (5) and (9), we find that

$$
\frac{c_{t}}{y_{t}}=\frac{1}{1+\gamma \eta}=0.8
$$

2. the time spent on leisure $\left(\ell_{t}\right)$ and procreation $\left(\phi \bar{N}^{\alpha}\right)$ amounts to $2 / 3$ of total available time (this has become a standard value in the literature since Ghez and Becker (1975) found that households allocate approximately one-third of their time to market activities). Using (13):

$$
\phi \bar{N}^{\alpha}=\frac{\gamma(1-\eta)}{1+\varphi+\gamma}
$$

From (6):

$$
\ell_{t}+\phi \bar{N}^{\alpha}=\frac{\varphi}{1+\varphi+\gamma}+\frac{\gamma(1-\eta)}{1+\varphi+\gamma}=\frac{\varphi+\gamma(1-\eta)}{1+\varphi+\gamma}=\frac{2}{3}
$$

3. At steady state, the time spent rearing children is equal to $15 \%$ (see de la Croix and Doepke (2003)) of the time remaining after leisure had been accounted for:

$$
\frac{\phi N^{\alpha}}{1-\ell_{t}}=0.15
$$

This implies

$$
\frac{\gamma(1-\eta)}{1+\gamma}=0.15
$$

4. Following the literature on conditional convergence (see Abreu, de Groot, and Florax (2005) for a survey), the convergence speed of income per capita is $2 \%$ per year. For the dynamic equation (11) we get

$$
\frac{k_{t+1}}{k_{t}}=\left(\frac{k_{t}}{k_{t-1}}\right)^{\nu+\eta}\left(\frac{N_{t}}{N_{t-1}}\right)^{\alpha \eta}
$$


The required convergence speed is obtained with $\nu+\eta=0.98^{25}$.

5. The dynamics of population are calibrated to match the forecasted evolution of world population between $2008(t-1), 2033(t)$ and $2058(t+1)$. From the dynamic equation (12) we get

$$
\frac{N_{t+1}}{N_{t}}=\left(\frac{N_{t}}{N_{t-1}}\right)^{1-\alpha}
$$

and we have $N_{t-1}=6.67, N_{t}=8.18$ and $N_{t+1}=8.88$ from the 2007 IIASA World Population Projection.

Solving this system gives $\gamma=0.470588, \varphi=2.27941, \eta=0.53125, \nu=0.0722147$, and $\alpha=0.5976$. Notice that $\eta$ is in line with estimates of the return from education (see the discussion in de la Croix and Doepke (2003)). Moreover, this $\eta$ is almost enough to obtain the required speed of convergence of income per capita, as the additional parameter $\nu$ is small. Notice finally that the parameter $\alpha$ implies an annual convergence speed for population of $3.56 \%$ per year.

The two productivity levels, $\tau$ and $\phi$, are parameters that determine the size of population and income per capita. Imposing initial conditions so as to start in 1983 requires $N_{0}=4.68$ and $y_{0}=4.541$. Inverting (9) gives us $k_{0}=16.0271$. In order to obtain the right levels $N_{1}=6.67$ and $y_{1}=7.614$ in 2008 , we need to have $\phi=0.0164$ and $\tau=24.0417$.

\subsection{Simulation}

Table 1 provides the simulation from 1983 (initial conditions) to 2208 when no pollution cap is imposed. It illustrates the properties of the benchmark model: monotonic convergence of population, which tends to 8.47 billions, and income per capita (38155 dollars per capita per year in 2208). Fertility declines rapidly to its replacement level. Leisure is constant.

Let us now impose a constant pollution cap:

$$
E^{\star}=100
$$

starting to bind in 2033 (one should read the 25 years period surrounding 2033). The chosen level of $E^{\star}$ is arbitrary and for illustration purposes only. Table 2 provides the results. There is now one new column: the pollution price $p_{t}$. The price in 2033 is 0.24 , corresponding to an implicit tax of $24 \%$ on production. Following the tax, total output $Y_{t}$ is indeed limited to 100. As a consequence of this tax, the households retreat from market activities to devote more time to leisure (66.1\% instead of $60.8 \%$ in the benchmark) and to procreation (1.151 child 


\begin{tabular}{rrrrrr}
\hline \hline$t$ & $N_{t}$ & $n_{t}$ & $\ell_{t}$ & $y_{t}$ & $Y_{t}$ \\
\hline 1983 & 4.680 & 1.425 & 0.608 & 5.342 & 25.002 \\
2008 & 6.670 & 1.153 & 0.608 & 9.769 & 65.164 \\
2033 & 7.692 & 1.059 & 0.608 & 15.737 & 121.052 \\
2058 & 8.146 & 1.023 & 0.608 & 21.954 & 178.847 \\
2083 & 8.336 & 1.009 & 0.608 & 27.334 & 227.862 \\
2108 & 8.414 & 1.004 & 0.608 & 31.428 & 264.432 \\
2133 & 8.445 & 1.002 & 0.608 & 34.290 & 289.596 \\
2158 & 8.458 & 1.001 & 0.608 & 36.185 & 306.058 \\
2183 & 8.463 & 1.000 & 0.608 & 37.397 & 316.498 \\
2208 & 8.465 & 1.000 & 0.608 & 38.155 & 322.992 \\
\hline \hline
\end{tabular}

Table 1: Benchmark Simulation - World Economy 1983-2208

\begin{tabular}{rrrrrrr}
\hline \hline$t$ & $N_{t}$ & $p_{t}$ & $n_{t}$ & $\ell_{t}$ & $y_{t}$ & $Y_{t}$ \\
\hline 1983 & 4.680 & 0.000 & 1.425 & 0.608 & 5.342 & 25.002 \\
2008 & 6.670 & 0.000 & 1.153 & 0.608 & 9.769 & 65.164 \\
2033 & 7.692 & 0.240 & 1.151 & 0.661 & 13.000 & 100.000 \\
2058 & 8.855 & 0.505 & 1.171 & 0.731 & 11.294 & 100.000 \\
2083 & 10.366 & 0.556 & 1.087 & 0.746 & 9.647 & 100.000 \\
2108 & 11.272 & 0.574 & 1.042 & 0.752 & 8.871 & 100.000 \\
2133 & 11.746 & 0.582 & 1.020 & 0.754 & 8.513 & 100.000 \\
2158 & 11.982 & 0.586 & 1.010 & 0.755 & 8.346 & 100.000 \\
2183 & 12.097 & 0.587 & 1.005 & 0.756 & 8.266 & 100.000 \\
2208 & 12.153 & 0.588 & 1.002 & 0.756 & 8.229 & 100.000 \\
\hline \hline
\end{tabular}

Table 2: Simulation with a Constant Pollution Cap - 1983-2208

\begin{tabular}{rrrrrrr}
\hline \hline$t$ & $N_{t}$ & $p_{t}$ & $n_{t}$ & $\ell_{t}$ & $y_{t}$ & $Y_{t}$ \\
\hline 1983 & 4.680 & 0.000 & 1.425 & 0.608 & 5.342 & 25.002 \\
2008 & 6.670 & 0.000 & 1.153 & 0.608 & 9.769 & 65.164 \\
2033 & 7.692 & 0.240 & 1.151 & 0.661 & 13.000 & 100.000 \\
2058 & 8.855 & 0.318 & 1.089 & 0.680 & 14.483 & 128.243 \\
2083 & 9.641 & 0.256 & 1.012 & 0.665 & 17.058 & 164.463 \\
2108 & 9.755 & 0.140 & 0.964 & 0.638 & 21.622 & 210.913 \\
2133 & 9.402 & 0.000 & 0.939 & 0.608 & 28.167 & 264.830 \\
2158 & 8.831 & 0.000 & 0.975 & 0.608 & 33.249 & 293.627 \\
2183 & 8.611 & 0.000 & 0.990 & 0.608 & 36.025 & 310.229 \\
2208 & 8.525 & 0.000 & 0.996 & 0.608 & 37.511 & 319.761 \\
\hline \hline
\end{tabular}

Table 3: Simulation with technical progress - 1983-2208 


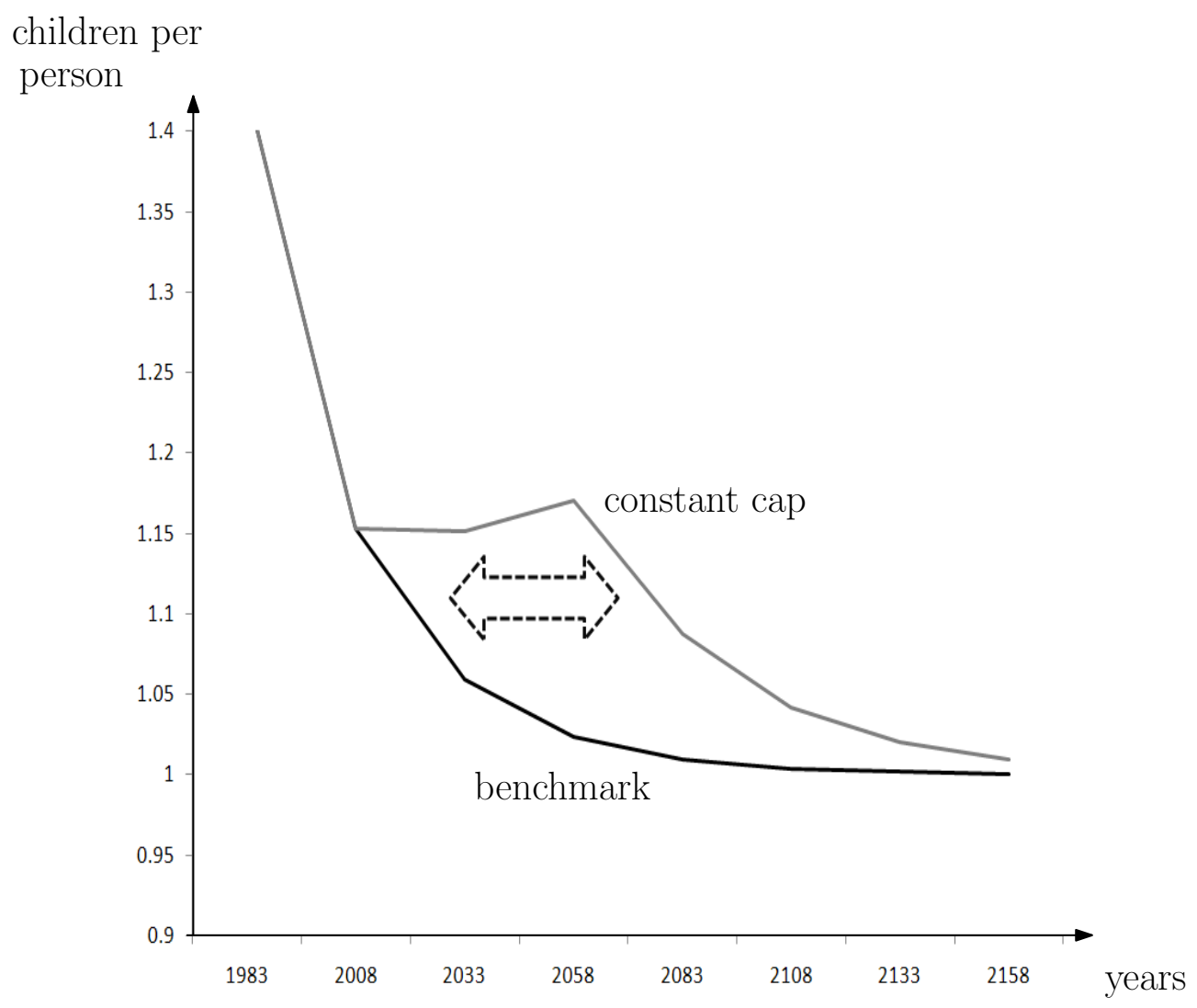

Figure 4: Delay in the Demographic Transition

per person instead of 1.059 in the benchmark, to be multiplied by 2 to compare to fertility rates per women). The rise in procreation does not look big, but it is large enough to have immense consequences for the future, through its cumulative effect over time. Population in 2058 is now 8.85 billions instead of 8.15 billions in the benchmark and converges in the long run to more than 12 billions instead of 8.5 billions in the benchmark.

Another way to look at the same data is to plot fertility over time. Figure 4 represents children born per person over time, for the benchmark (black line) and the constant cap (grey line) scenarii. The drop is fertility is delayed by two periods when the pollution cap is imposed. Notice that delaying the demographic transition does not entail reversing the general trend towards fertility drop. This matters for the following reason. Data tend to show that countries having gone through their demographic transition do not experience later on a rise in fertility in episodes of impoverishment (see e.g. Moldova). This could suggest that the demographic transition is irreversible. Even if we were to accept this idea, this would not conflict with the delaying effect we identified. 
Suppose now that there is some technical progress making production more and more clean over time. Precisely, we assume that

$$
a_{t}=(1.01)^{-25(t-2)}
$$

which reflects a technical progress of $1 \%$ per year. $t$ is equal to 2 in 2033 , this formulation is the same as previously for the year 2033, but output is becoming less and less polluting as time passes. Hence we can allow increasing caps: $E_{2033}^{\star}=100, E_{2058}^{\star}=128.243$ etc. Table 3 provides the results. In the long-run, the cap is not binding thanks to technical progress, and the economy converges to the benchmark steady state. As population has risen fast in the beginning, it actually overshoot its long run level, and converges from above to its steady state. The cost of this policy in terms of income are still very large. For example, income per person would be 17058 dollars per year in 2083 with the cap, and 27334 in the benchmark.

Figure 5 summarizes the result, comparing the benchmark, the constant pollution cap, and the increasing cap simulations on the figure used in the introduction to present the isopollution curve. The benchmark follows a convex path in this plane, and crosses the isopollution line $E^{\star}=100$ early on. The constant cap path, on the contrary, moves South-East as soon as the cap is binding. It will converge to a situation with a large population and an income per capita only slightly above the 1983 level. The increasing cap path is an intermediate case. In the short-run (which means here a few generations), it follows the constant cap path, with lower income per person and higher population. In the long-run though, the path converges to the benchmark steady state.

In future research, it would be interesting to consider a policy under which we cap population rather than emissions, for example along the lines proposed by de la Croix and Gosseries (2009). Tradable procreation quotas schemes are of course not the only available option. Policies aimed at addressing population issues - both in terms of absolute level and of heterogeneity - are notoriously difficult to design. If they aim at keeping population below a certain level, they should remain as freedom-friendly as possible while being simultaneously concerned with not increasing poverty and inequality. Women education is a policy that can be justified independently (e.g. on gender equality grounds) while being effective at reducing birth rate without increasing poverty nor infringing too much on procreative freedom. Other tools have been discussed in the literature, such as taxing skilled people to subsidize unskilled ones ready to limit themselves to a single child (Fan and Stark (2008)).

While it is beyond the scope of this paper to explore the respective merits of such population 
Income per cap.

thousands usd

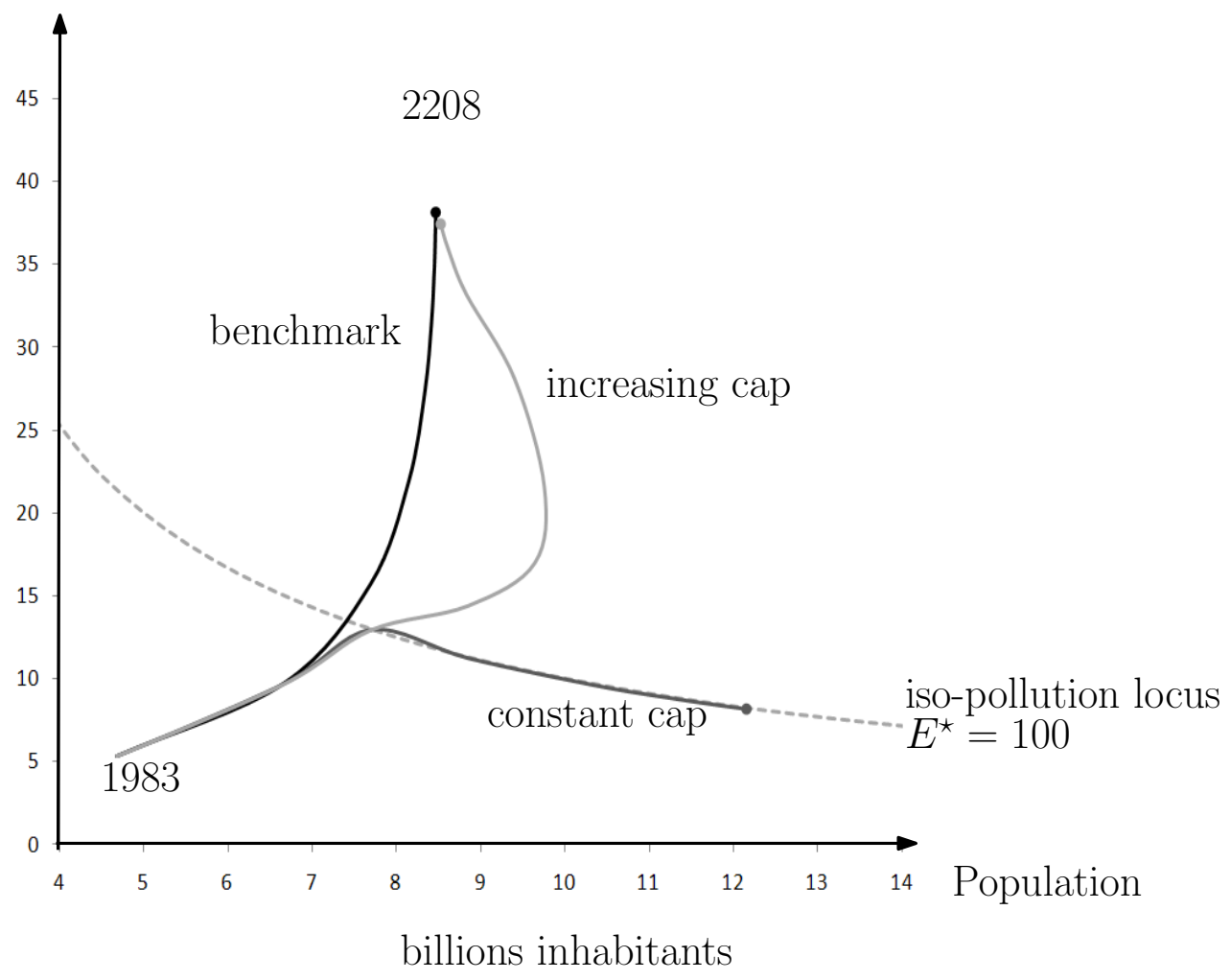

Figure 5: Income and Population Dynamics in the Examples

control policies in detail, it would of course be crucial to consider which one to adopt in conjunction with measures of pollution control. Alternatively, a population control policy could also work as a substitute to a directly environmental one. A key question is the following: is there a population cap $N^{\star}$ such that the desired emission level $E^{\star}$ could be met? If yes, does $N^{\star}$ allow for higher income per capita than under the model capping emissions directly? If the answer to these two questions is positive, the next question will become: under which conditions does it follow that we should cap population rather than emissions?

\section{Conclusion}

Pollution control, and especially greenhouse gas emission reduction, are matters of great importance. Most of the literature looks at environmental policy considering that demography is exogenous (see e.g. the two influential papers by Howarth (1998) and Gerlagh and van der 
Zwaan (2001) using OLG models). However, we have shown that such policies unexpectedly impact on the population dynamics through a production-procreation substitution effect. Capping pollution subsidies de facto procreation, and may therefore delay the demographic transition in developing countries and the drop in global fertility. Such an increase in population, compared with a business as usual scenario, may in turn be damaging either in environmental terms if the pollution scheme is ineffective, or in terms of average standard of living - both independently and through the operation of the pollution cap at the next period.

Admittedly, the effect of pollution on utility and/or on productivity has not been modeled. If pollution affects productivity negatively, ${ }^{9}$ or has a negative effect on the health of workers, the strength of our substitution effect would be weakened. Assuming that consumption and environment quality are complements in the utility function would also weaken our results. Refining the model in that direction would definitely be of interest for a welfare assessment of environmental policies. However, it would not affect the specific conclusion of this paper, as these extensions are unlikely to reverse the direction of the substitution effect we highlighted. Moreover, we assumed that households do not care about future generations beyond their own children. This is not an unusual assumption as some degree of diminishing altruistic behavior seems realistic. Finally, we have considered technological progress to be exogenous. This does not put into question the fact that capping pollution has an impact on population, and even a significant one as we have shown, even if technological progress were endogenous. We need to make sure as much as possible that pollution control does not take place at the costs of the current least well off or at the cost of those in the future. The natalist bias we identified is worrying in the latter respect. One may then want to address it in two main ways. As was suggested in the introduction, one could adopt an allocation rule of pollution endowments relying on some form of emission grandfathering. It would be such that those deciding to increase their population would not receive extra emission quotas at the next period. Besides the fairness concerns that this would raise, it may however not be enough to mitigate the substitution effect to a significant degree. Alternatively, population could be capped directly through a separate scheme, be it in the absence of or as a complement of the pollution capping scheme. Further research is needed to assess the impact of using population and pollution capping schemes either alternatively or complementarily. ${ }^{10}$

\footnotetext{
${ }^{9}$ One possibility would be for example to model the impact of emissions on agricultural productivity through average temperature increase.

${ }^{10}$ Another possible extension of the model would consist in adding income heterogeneity among households within generations. This would allow us to study the distributive impact of the substitution effect.
} 


\section{References}

Abreu, Maria, Henri de Groot, and Raymond Florax. 2005. "A Meta-Analysis of $\beta$ Convergence: the Legendary 2\%." Journal of Economic Surveys 19 (3): 389-420.

Andreoni, James. 1989. "Giving with impure altruism: applications to charity and Ricardian equivalence." Journal of Political Economy 97 (6): 1447-1459.

Bar, Michael, and Oksana Leukhina. 2010. "Demographic Transition and Industrial Revolution: A Macroeconomic Investigation." Review of Economic Dynamics 13 (2): 424-451.

Baudin, Thomas. 2009. "Religion and Fertility: The French Connection." CORE mimeo.

Becker, Gary S. 1960. "An Economic Analysis of Fertility." Demographic and Economic Change in Developed Countries. Princeton: Princeton University Press.

Becker, Gary S., and H. Gregg Lewis. 1973. "On the Interaction between the Quantity and Quality of Children." Journal of Political Economy 81 (2): S279-88.

Deb, Partha, and Furio Rosati. 2004. "Estimating the effect of fertility decisions on child labor and schooling." unpublished manuscript.

de la Croix, David, and Matthias Doepke. 2003. "Inequality and Growth: Why Differential Fertility Matters." American Economic Review 93 (4): 1091-113.

— 2009. "To Segregate or to Integrate: Education Politics and Democracy." Review of Economic Studies 76:597-628.

de la Croix, David, and Davide Dottori. 2008. "Easter Island's collapse: a tale of a population race." Journal of Economic Growth 13 (1): 27-55.

de la Croix, David, and Axel Gosseries. 2009. "Population Policy through Tradable Procreation Entitlements." International Economic Review 50:507-542.

Doepke, Matthias. 2004. "Accounting for Fertility Decline During the Transition to Growth." Journal of Economic Growth 9 (3): 347-83.

- 2005. "Child mortality and fertility decline: Does the Barro-Becker model fit the facts?" Journal of Population Economics 18 (2): 337-366.

Ehrlich, Isaac, and Francis T. Lui. 1991. "Intergenerational Trade, Longevity, and Economic Growth." Journal of Political Economy 99 (5): 1029-59.

Fan, C. Simon, and Oded Stark. 2008. "Looking At The Population Problem Through The Prism Of Heterogeneity: Welfare And Policy Analyses." International Economic Review 49 (3): 799-835. 
Fernández, Raquel, and Alessandra Fogli. 2006. "Fertility: The Role of Culture and Family Experience." Journal of the European Economic Association 4 (2-3): 552-561.

Garvey, James. 2008. The Ethics of Climate Change. Right and wrong in a warming world. London/New York: Continuum.

Gerlagh, Reyer, and Bob van der Zwaan. 2001. "The effects of ageing and an environmental trust fund in an overlapping generations model on carbon emission reductions." Ecological Economics 36 (2): 311 - 326.

Ghez, Gilbert, and Gary S. Becker. 1975. The Allocation of Time and Goods over the Life Cycle. NBER Books. National Bureau of Economic Research, Inc.

Glomm, Gerhard, and B. Ravikumar. 1992. "Public Versus Private Investment in Human Capital: Endogenous Growth and Income Inequality." Journal of Political Economy 100 (4): 818-834.

Goodsell, Willystine. 1937. "Housing and birth rate in Sweden." American Sociological Review 2 (6): 850-859.

Grubb, Michael. 1995. "Seeking Fair Weather: Ethics and the International Debate on Climate Change." International Affairs 71 (3): 463-496.

Howarth, Richard B. 1998. "An Overlapping Generations Model of Climate-Economy Interactions." Scandinavian Journal of Economics 100 (3): 575-91.

John, Andrew, and Rowena Ann Pecchenino. 1994. "An Overlapping Generations Model of Growth and the Environment." Economic Journal 104 (427): 1393-1410.

Jones, Larry E., Alice Schoonbroodt, and Michèle Tertilt. 2010. "Fertility Theories: Can They Explain the Negative Fertility-Income Relationship?" In Demography and the Economy, NBER Chapters, 43-100. National Bureau of Economic Research, Inc.

Krueger, Alan B., and Mikael Lindahl. 2001. "Education and Growth: Why and for Whom?" Journal of Economic Literature 39 (4): 1101-36.

Leibowitz, Arleen. 1974. "Home Investments in Children." Journal of Political Economy 82 (2): S111-S131.

Moav, Omer. 2005. "Cheap Children and the Persistence of Poverty." Economic Journal 115 (500): 88-110.

Newell, Richard G., Adam B. Jaffe, and Robert N. Stavins. 1999. "The Induced Innovation Hypothesis And Energy-Saving Technological Change." The Quarterly Journal of Economics 114 (3): 941-975. 
Popp, David. 2002. "Induced Innovation and Energy Prices." American Economic Review 92 (1): 160-180.

Prescott, Edward C. 1986. "Theory ahead of business-cycle measurement." CarnegieRochester Conference Series on Public Policy 25 (1): 11-44.

Shi, Yuhua, and Jie Zhang. 2009. "On high fertility rates in developing countries: birth limits, birth taxes, or education subsidies?" Journal of Population Economics 22 (3): 603-640.

Thompson, Warren S. 1938. "The effect of housing upon population growth." The Milbank Memorial Fund Quarterly 16 (4): 359-368.

Toft, Monica D. 2002. "Differential Demographic Growth in Multinational States: Israel's Two-Front War." Journal of International Affairs 56:71-94.

Weitzman, Martin. 1974. "Prices vs. Quantities." Review of Economic Studies 41:477-491.

Wirl, Franz. 2011. "Global Warming: Prices versus Quantities from a Strategic Point of View." University of Vienna.

\section{A Dynamics in the Small Open Economy}

The dynamics to characterize are given by:

$$
\begin{aligned}
k_{t+1} & =\tau\left(\frac{\eta \varphi}{1-\eta}\right)^{\eta} N_{t}^{\eta \alpha} k_{t}^{\nu+\eta}(1-a p)^{\eta} \\
N_{t+1} & =\frac{\gamma(1-\eta)}{(1+\varphi+\gamma) \phi} N_{t}^{1-\alpha} \frac{(1-a p) k_{t}+p q}{(1-a p) k_{t}}
\end{aligned}
$$

Linearizing the dynamic system around the steady state $(\bar{k}, \bar{N})$ and using the steady state relationships leads to the following Jacobian matrix:

$$
\left[\begin{array}{ll}
\eta+\nu & \frac{p q \alpha \gamma \eta(1-\eta)}{\bar{N}(p-1)\left(\gamma(1-\eta)-\bar{N}^{\alpha}(\gamma+\varphi+1) \phi\right)} \\
\frac{\bar{N}^{1-\alpha}(p-1)\left(\gamma(1-\eta)-\bar{N}^{\alpha}(\gamma+\varphi+1) \phi\right)^{2}}{p q \gamma(\gamma+\varphi+1)(1-\eta) \phi} & 1-\alpha
\end{array}\right]
$$

The determinant of this matrix is:

$$
-\frac{\alpha \gamma \eta(1-\eta) \bar{N}^{-\alpha}}{(1+\gamma+\varphi) \phi}+\eta-\alpha \nu+\nu
$$


It is smaller than one and increasing in $\bar{N}$. We need to show that it is larger than -1 to establish local stability. For a steady state not too far from the one in the benchmark model

$$
\left(\frac{\gamma(1-\eta)}{(1+\varphi+\gamma) \phi}\right)^{\frac{1}{\alpha}}
$$

(Equation 13), the determinant is:

$$
-\alpha \eta+\eta-\alpha \nu+\nu=(\eta+\nu)(1-\alpha) \in(0,1)
$$

Hence, for a larger value of steady state population, the determinant is also $\in(0,1)$.

The trace of the Jacobian matrix is:

$$
1-\alpha+\eta+\nu \in(0,2)
$$

Hence, the two eigenvalues are positive and smaller than one, and the steady state is locally stable.

\section{B Dynamics in the Global Economy}

The dynamics to characterize are given by:

$$
\begin{aligned}
k_{t+1} & =\tau k_{t}^{\nu+\eta}\left(\frac{\eta \phi N_{t}^{\alpha} E^{\star}(\varphi+\gamma-\gamma \eta)}{\left(N_{t} k_{t}-E^{\star}\right)(1-\eta)(1+\gamma \eta)}\right)^{\eta} \\
N_{t+1} & =\frac{\gamma(1-\eta)\left(N_{t} k_{t}-E^{\star}\right)}{\phi N_{t}^{\alpha} k_{t}(\varphi+\gamma-\gamma \eta)}
\end{aligned}
$$

To analyze these dynamics let us first look for steady states. Solving the last equation for $k$ at steady state leads to:

$$
\bar{k}=\frac{\gamma(1-\eta) E^{\star} / N}{\gamma(1-\eta)-\phi N^{\alpha}(\varphi+\gamma-\gamma \eta)}
$$

Replacing $k_{t+1}$ and $k_{t}$ by this value in the first dynamic equation, we find:

$$
\tau\left(\frac{\bar{N}}{E^{\star}}\right)^{1-\nu-\eta}\left(\frac{\gamma \eta}{1+\gamma \eta}\right)^{\eta}=\left(\frac{\gamma(1-\eta)}{\gamma(1-\eta)-\phi \bar{N}^{\alpha}(\gamma+\varphi-\gamma \eta)}\right)^{1-\nu}
$$

This equation cannot be solved explicitly for $\bar{N}$. Let us rewrite this equality as

$$
\Psi_{1}\left(E^{\star}, \bar{N}\right)=\Psi_{2}(\bar{N})
$$




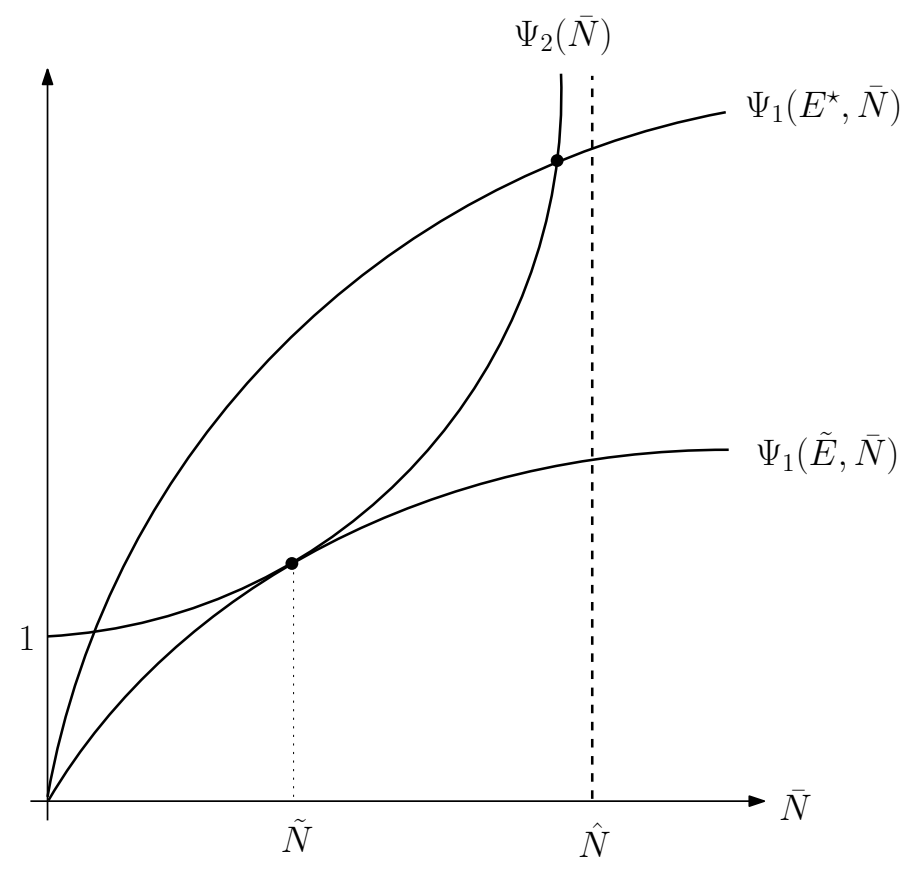

Figure 6: Steady State Population with Pollution Cap

Figure 6 represents these two functions. The left hand side $\Psi_{1}$ is an increasing and concave function of $\bar{N}$, starting from 0 when $\bar{N}=0$ and going to infinity as $\bar{N} \rightarrow \infty$. The right hand side $\Psi_{2}$ is an increasing and convex function of $\bar{N}$, starting from 1 when $\bar{N}=0$ and going to infinity as $\bar{N} \rightarrow \hat{N}$ (vertical asymptote), with

$$
\hat{N}=\left(\frac{\gamma(1-\eta)}{\phi(\gamma+\varphi-\gamma \eta)}\right)^{1 / \alpha}
$$

Hence, given the characteristics of the two functions, there are either two, one or no steady state, depending on the stringency of the cap $E^{\star}$.

We can show that, when the cap $E^{\star}$ is set at its most stringent and yet non binding level, i.e. such that $p=0$ and $y=q$, the steady state is unique. Indeed, in that case,

$$
E=N k \frac{1+\gamma \eta}{1+\varphi+\gamma}
$$


Equation (23) would be, in that case,

$$
\begin{aligned}
\tau\left(\frac{1+\varphi+\gamma}{1+\gamma \eta}\left(\frac{\tau^{1 / \eta} \gamma \eta}{1+\varphi+\gamma}\right)^{\frac{-\eta}{1-\nu-\eta}}\right)^{1-\nu-\eta}\left(\frac{\gamma \eta}{1+\gamma \eta}\right)^{\eta} & =\left(\frac{\gamma(1-\eta)}{\gamma(1-\eta)-\phi \bar{N}^{\alpha}(\gamma+\varphi-\gamma \eta)}\right)^{1-\nu}
\end{aligned}
$$

which simplifies into

$$
\frac{1+\varphi+\gamma}{1+\gamma \eta}=\frac{\gamma(1-\eta)}{\gamma(1-\eta)-\phi \bar{N}^{\alpha}(\gamma+\varphi-\gamma \eta)}
$$

and

$$
\bar{N}=\left(\frac{\gamma(1-\eta)}{(1+\varphi+\gamma) \phi}\right)^{\frac{1}{\alpha}} \equiv \tilde{N}
$$

is the only solution to this equality. $\bar{N}$ and $\bar{k}$ take their value as in the benchmark model without pollution cap.

Making the pollution cap $E^{\star}$ marginally more stringent shifts the $\Psi_{1}$ function upward. As a result, for any binding pollution cap, we end up with two possible steady state equilibria, respectively one with a larger population than $\tilde{N}$ and one with a smaller. A further step is needed to identify a stable steady state and demonstrate the pro-natalist effect of lowering $E^{\star}$.

Linearizing the dynamic system around the steady state leads to the following Jacobian matrix:

$$
\left[\begin{array}{ll}
\eta+\nu-\frac{\gamma \eta(1-\eta)}{(\varphi+\gamma-\eta \gamma) \phi \bar{N}^{\alpha}} & -\frac{E^{\star} \gamma \eta(1-\eta)\left(\gamma(1-\eta)-\alpha(\varphi+\gamma-\eta \gamma) \phi \bar{N}^{\alpha}\right)}{\bar{N}^{2}(\varphi+\gamma-\eta \gamma) \phi \bar{N}^{\alpha}\left((\varphi+\gamma-\eta \gamma) \phi \bar{N}^{\alpha}+\gamma(1-\eta)\right)} \\
\frac{\bar{N}^{2}\left(\gamma(1-\eta)-(\varphi+\gamma-\eta \gamma) \phi \bar{N}^{\alpha}\right)^{2}}{E^{\star} \gamma(\varphi+\gamma-\eta \gamma)(1-\eta) \phi N^{\alpha}} & \frac{\gamma(1-\eta)}{(\varphi+\gamma-\eta \gamma) \phi N^{\alpha}}-\alpha
\end{array}\right]
$$

The determinant of this matrix is:

$$
\frac{\gamma(1-\eta) \nu}{(\varphi+\gamma-\eta \gamma) \phi \bar{N}^{\alpha}}-\alpha \nu
$$

It is decreasing in $\bar{N}$. Its trace is:

$$
\frac{\gamma(1-\eta)^{2}}{(\varphi+\gamma-\eta \gamma) \phi \bar{N}^{\alpha}}-\alpha+\eta+\nu
$$

also decreasing in $\bar{N}$. 
For the steady state close to $\hat{N}$, the determinant has a value close to $\nu(1-\alpha)$ and a trace close to $1-\alpha+\nu$. It is is therefore locally stable.

If $E^{\star}$ is restrictive enough, the low population steady state has a population close to zero, and the high population steady state has a population close to the value of the vertical asymptote $\hat{N}$. The low population steady state is increasing in $E^{\star}$, the high population steady state, which is locally stable, is decreasing in $E^{\star}$. The latter result proves Proposition 2. 


\section{Recent titles \\ CORE Discussion Papers}

2010/72. Olivier GERGAUD and Victor GINSBURGH. Success: talent, intelligence or beauty?

2010/73. Jean GABSZEWICZ, Victor GINSBURGH, Didier LAUSSEL and Shlomo WEBER. Foreign languages' acquisition: self learning and linguistic schools.

2010/74. Cédric CEULEMANS, Victor GINSBURGH and Patrick LEGROS. Rock and roll bands, (in)complete contracts and creativity.

2010/75. Nicolas GILLIS and François GLINEUR. Low-rank matrix approximation with weights or missing data is NP-hard.

2010/76. Ana MAULEON, Vincent VANNETELBOSCH and Cecilia VERGARI. Unions' relative concerns and strikes in wage bargaining.

2010/77. Ana MAULEON, Vincent VANNETELBOSCH and Cecilia VERGARI. Bargaining and delay in patent licensing.

2010/78. Jean J. GABSZEWICZ and Ornella TAROLA. Product innovation and market acquisition of firms.

2010/79. Michel LE BRETON, Juan D. MORENO-TERNERO, Alexei SAVVATEEV and Shlomo WEBER. Stability and fairness in models with a multiple membership.

2010/80. Juan D. MORENO-TERNERO. Voting over piece-wise linear tax methods.

2010/81. Jean HINDRIKS, Marijn VERSCHELDE, Glenn RAYP and Koen SCHOORS. School tracking, social segregation and educational opportunity: evidence from Belgium.

2010/82. Jean HINDRIKS, Marijn VERSCHELDE, Glenn RAYP and Koen SCHOORS. School autonomy and educational performance: within-country evidence.

2010/83. Dunia LOPEZ-PINTADO. Influence networks.

2010/84. Per AGRELL and Axel GAUTIER. A theory of soft capture.

2010/85. Per AGRELL and Roman KASPERZEC. Dynamic joint investments in supply chains under information asymmetry.

2010/86. Thierry BRECHET and Pierre M. PICARD. The economics of airport noise: how to manage markets for noise licenses.

2010/87. Eve RAMAEKERS. Fair allocation of indivisible goods among two agents.

2011/1. Yu. NESTEROV. Random gradient-free minimization of convex functions.

2011/2. Olivier DEVOLDER, François GLINEUR and Yu. NESTEROV. First-order methods of smooth convex optimization with inexact oracle.

2011/3. Luc BAUWENS, Gary KOOP, Dimitris KOROBILIS and Jeroen V.K. ROMBOUTS. A comparison of forecasting procedures for macroeconomic series: the contribution of structural break models.

2011/4. Taoufik BOUEZMARNI and Sébastien VAN BELLEGEM. Nonparametric Beta kernel estimator for long memory time series.

2011/5. Filippo L. CALCIANO. The complementarity foundations of industrial organization.

2011/6. Vincent BODART, Bertrand CANDELON and Jean-François CARPANTIER. Real exchanges rates in commodity producing countries: a reappraisal.

2011/7. Georg KIRCHSTEIGER, Marco MANTOVANI, Ana MAULEON and Vincent VANNETELBOSCH. Myopic or farsighted? An experiment on network formation.

2011/8. Florian MAYNERIS and Sandra PONCET. Export performance of Chinese domestic firms: the role of foreign export spillovers.

2011/9. Hiroshi UNO. Nested potentials and robust equilibria.

2011/10. Evgeny ZHELOBODKO, Sergey KOKOVIN, Mathieu PARENTI and Jacques-François THISSE. Monopolistic competition in general equilibrium: beyond the CES.

2011/11. Luc BAUWENS, Christian HAFNER and Diane PIERRET. Multivariate volatility modeling of electricity futures.

2011/12. Jacques-François THISSE. Geographical economics: a historical perspective.

2011/13. Luc BAUWENS, Arnaud DUFAYS and Jeroen V.K. ROMBOUTS. Marginal likelihood for Markov-switching and change-point GARCH models. 


\section{Recent titles}

\section{CORE Discussion Papers - continued}

2011/14. Gilles GRANDJEAN. Risk-sharing networks and farsighted stability.

2011/15. Pedro CANTOS-SANCHEZ, Rafael MONER-COLONQUES, José J. SEMPERE-MONERRIS and Oscar ALVAREZ-SANJAIME. Vertical integration and exclusivities in maritime freight transport.

2011/16. Géraldine STRACK, Bernard FORTZ, Fouad RIANE and Mathieu VAN VYVE. Comparison of heuristic procedures for an integrated model for production and distribution planning in an environment of shared resources.

2011/17. Juan A. MAÑEZ, Rafael MONER-COLONQUES, José J. SEMPERE-MONERRIS and Amparo URBANO Price differentials among brands in retail distribution: product quality and service quality.

2011/18. Pierre M. PICARD and Bruno VAN POTTELSBERGHE DE LA POTTERIE. Patent office governance and patent system quality.

2011/19. Emmanuelle AURIOL and Pierre M. PICARD. A theory of BOT concession contracts.

2011/20. Fred SCHROYEN. Attitudes towards income risk in the presence of quantity constraints.

2011/21. Dimitris KOROBILIS. Hierarchical shrinkage priors for dynamic regressions with many predictors.

2011/22. Dimitris KOROBILIS. VAR forecasting using Bayesian variable selection.

2011/23. Marc FLEURBAEY and Stéphane ZUBER. Inequality aversion and separability in social risk evaluation.

2011/24. Helmuth CREMER and Pierre PESTIEAU. Social long term care insurance and redistribution.

2011/25. Natali HRITONENKO and Yuri YATSENKO. Sustainable growth and modernization under environmental hazard and adaptation.

2011/26. Marc FLEURBAEY and Erik SCHOKKAERT. Equity in health and health care.

2011/27. David DE LA CROIX and Axel GOSSERIES. The natalist bias of pollution control.

\section{Books}

P. VAN HENTENRYCKE and L. WOLSEY (eds.) (2007), Integration of AI and OR techniques in constraint programming for combinatorial optimization problems. Berlin, Springer.

P-P. COMBES, Th. MAYER and J-F. THISSE (eds.) (2008), Economic geography: the integration of regions and nations. Princeton, Princeton University Press.

J. HINDRIKS (ed.) (2008), Au-delà de Copernic: de la confusion au consensus ? Brussels, Academic and Scientific Publishers.

J-M. HURIOT and J-F. THISSE (eds) (2009), Economics of cities. Cambridge, Cambridge University Press.

P. BELLEFLAMME and M. PEITZ (eds) (2010), Industrial organization: markets and strategies. Cambridge University Press.

M. JUNGER, Th. LIEBLING, D. NADDEF, G. NEMHAUSER, W. PULLEYBLANK, G. REINELT, G. RINALDI and L. WOLSEY (eds) (2010), 50 years of integer programming, 1958-2008: from the early years to the state-of-the-art. Berlin Springer.

G. DURANTON, Ph. MARTIN, Th. MAYER and F. MAYNERIS (eds) (2010), The economics of clusters Lessons from the French experience. Oxford University Press.

J. HINDRIKS and I. VAN DE CLOOT (eds) (2011), Notre pension en heritage. Itinera Institute.

\section{CORE Lecture Series}

D. BIENSTOCK (2001), Potential function methods for approximately solving linear programming problems: theory and practice.

R. AMIR (2002), Supermodularity and complementarity in economics.

R. WEISMANTEL (2006), Lectures on mixed nonlinear programming. 